\title{
Early Appraisal of Option B+ In Tiko Health District- Cameroon
}

\author{
${ }^{1}$ Tassang Andrew, ${ }^{2}$ Nana Njamen T, ${ }^{3}$ Assop, ${ }^{4}$ Tassang Thierry, ${ }^{5}$ Njamen Nana CJ, ${ }^{6}$ Ngum Fru \\ Paulette, ${ }^{7}$ Cho Frederick Nchang \\ ${ }^{1,2,3,6,7}$ Faculty of Health Sciences, University of Buea Cameroon. Regional Hospital annex - Buea \\ ${ }^{2}$ Douala General Hospital \\ ${ }^{1,4}$ Atlantic Medical Foundation Hospital, Mutengene \\ ${ }^{4}$ Regional Hospital Annex, Buea \\ ${ }^{5}$ Faculty of Medicine, University of Heidelberg Germany \\ ${ }^{1,4}$ District hospital Kumbo
}

\begin{abstract}
Introduction: Cameroon in 2014 had an HIV prevalence rate of $4.6 \%$. An estimated $90 \%$ of new infections occur as a result of heterosexual relations. In 2010 in Cameroon, an estimated 7300 babies were born HIV positive due to mother-to-child transmission (MTCT). Faced with these realities, Cameroon has been stepping up its response steadily from Option A then B and now Option B+. Our aim is to have an initial appraisal of the Option $\mathrm{B}+$ approach as far as the prevention of mother to child transmission of HIV (PMTCT) is concerned in the Tiko health district- Cameroon.
\end{abstract}

Methodology: This cross-sectional hospital-based study was done in Tiko from the 1st of December 2015 to the 31st of August 2016. With the use of a questionnaire, a total of 111 women whose infants underwent the polymerase chain reaction (PCR) test at six weeks were surveyed. Univariate and bivariate data analysis were done with CDC- Epi-Info 7.2.2.6.

Results: Out of 111 women included in this study, only $2(1.8 \%)$ babies had a positive PCR test. Two cases of infected babies were realized in the study, 1 in each of the first two trimesters of pregnancy. It could probably be because these women got infected while they were already pregnant or maybe before their introduction to the Option $\mathrm{B}+$. However, the infectious rate was similar to that of women on tritherapy. Interventions like the use of Antiretroviral (ART) drugs by infected pregnant women, safe delivery practices, and safe infant feeding helped reduce the risk of transmission to infants (from $40 \%$ to $5 \%)$.

Conclusion: The infection rate of $1.8 \%$ is similar to those of women who are on tritherapy in many studies. Even though the implementation of option B+ looks more onerous, the long term benefits as far as cost-effectiveness is concerned lookla udable. Thus this strategy should be adopted in resource-restricted countries.

Keywords: PMTC, Option B+, C Reactive Protein, Tiko health district, Cameroon.

\section{Introduction}

Acquired Immuno-deficiency Syndrome (AIDS) caused by the human immuno-deficiency virus (HIV) . This virus has become a significant public health challenge in Africa as a whole and Sub-Saharan Africa, in particular. Africa has about $15.2 \%$ of the world's population, but Sub-Saharan Africa alone harbors about 25 million People Living with HIV, representing about $69 \%$ of infected cases and $70 \%$ of the total number of deaths in the world [1-4].

The prevalence of HIV in Cameroon ranges between $4.5 \%$ [5] to $4.6 \%[6,7]$ and is $7.6 \%$ among pregnant women [8]. 7,300 babies were estimated to be born HIV positive due to mother-to-child transmission (MTCT) [7]. 
Faced with these realities, Cameroon steadily stepped-up response from Option A then B and now Option $\mathrm{B}+$ in the fight to optimize its approach towards the prevention of mother to child transmission of HIV (PMTCT) [7-9]. It is anticipated that by 2020, the number of children affected by AIDS will increase beyond 350,000 in Cameroon [7, 9, 10]. Hence, the preoccupation of this study was for an early appraisal of the Option B+ approach as far as the PMTCT is concerned in the Tiko Health District (THD) - Cameroon.

\section{Materials And Methods}

\section{Study area}

The study was done in the THD, in the South West Region of Cameroon. Tiko is situated about some $18 \mathrm{Km}$ away from Buea, the South West Regional capital, and it is both an administrative headquarter, Tiko SubDivision, and a Health District; Tiko Health District.

The THD with an estimated population of 334,647 is distributed in eight health areas, and has a total surface area of $4,840 \mathrm{Km}^{2}$, yielding an average population density of 28 inhabitants per $\mathrm{Km}^{2}$ for the Municipality [11]. Tiko's health area constitutes of 28 villages or agglomerations, among which three are well thoughtout as urban settlements; Tiko, Likomba, and Mutengene. The THD is bounded to the West by the Limbe health district, to the North by the Buea health district, to the North-East by Muyuka health district, to the East by the Dibombari health district in Mungo Division and to the South by Bonaberi health district in Wouri division $[12,13]$.

\section{Study and sampling design}

This was a cross-sectional study carried out between the $1^{\text {st }}$ of December 2015 and $31^{\text {st }}$ of August 2016 in the THD. Study participants from eight health institutions prospectively enrolled within the study period.

The health institutions wherein the study was done were sampled by simple random sampling, and participants sampled by convenience.

\section{Study population}

Eligible study participants were pregnant women and mothers of the reproductive ages. Subjects on whose babies were not assayed for HIV by the Polymerase Chain Reaction (PCR) within six weeks were excluded from the study.

\section{Ethical consideration}

Ethical clearance and approval were obtained from the Institutional Review Board of the University of Buea, and the Regional Delegation of the Ministry of Health, as well as administrators of the various health institutions wherein this study, was carried out. All participants provided written informed consent before enrolment.

\section{Statistical analysis}

Pre-tested structured questionnaires were used for data collection. Sociodemographic data of mother; marital status, occupation, educational level, number of children, duration of pregnancy, and PCR status of the baby were recorded. Data collected was keyed into CDC- Epi-Info version 7.2.2.6 (Centre for Disease Control, Georgia USA) for analysis, and statistical significance set at $p \leq 0.05$.

\section{Some definitions}

Option B+ approach: advocates for the systematic initiation of antiretroviral tritherapy (universal test and treat) for HIV positive pregnant or breastfeeding women regardless of the clinical and immunological stage (CD4). ART should be continued throughout pregnancy, delivery, and life [8, 14, 15]. Sero-positive women were placed on Tenofovir, Lamivudine, and Efavirenz/ Nevirapine (depending on the gestational age) [8, 16-19].

Dosage of Niverapine in HIV exposed infants: From birth to 6 weeks (birth weight 2000-2499 g); $10 \mathrm{mg}$ (1 $\mathrm{mL}$ ), for birth weight superior to $2500 \mathrm{~g} ; 15 \mathrm{mg}$ (1.5 mL), from six weeks to six months; $20 \mathrm{mg}$, from six months to nine months; $30 \mathrm{mg}$, from nine months till the end of breastfeeding, $40 \mathrm{mg}(4 \mathrm{~mL})$ administered once daily. In children with low birth weight $(<2000 \mathrm{~g})$, start with $0.2 \mathrm{~mL}$ per day until the child attains 2000g [8]. Babies feeding should exclusively be breastfed or artificially fed where it is acceptable, feasible, accessible, affordable, and sustainable. Mixed feeding is not recommended. 
Dry blood spots $(D B S)$ : small volumes of blood were collected onto filter paper from the heel at six weeks to four months and from the big toe from $4-10$ months, using the kit manufactured by MiMEDA -

Heidelberg, Germany. The DBS was then processed according to manufacturer's instructions and shipped to the CDC/DGHA-Cameroon (US Centres for Disease Control and Prevention), laboratory situated at Mutengene, South West region of Cameroon.

\section{Results}

Characteristics of the study participants

A total of 111 participants were sampled with 98 children in their homes, across three health areas in the Tiko Health District. The mean weight $( \pm \mathrm{SD})$ of neonates in the study was $2.7 \pm 0.3 \mathrm{Kg}$. Sociodemographic characteristics were summarized in Table1.

Table 1: Sociodemographic characteristics: by health areas

\begin{tabular}{|c|c|c|c|c|c|c|}
\hline \multirow[b]{2}{*}{ Characteristic } & \multicolumn{3}{|c|}{ Health area } & \multirow[b]{2}{*}{ Total } & \multirow[b]{2}{*}{$\chi^{2}$} & \multirow[b]{2}{*}{$p$ value } \\
\hline & Holforth & Likomba & Tiko & & & \\
\hline AGE GROUPS & $n=48$ & $n=49$ & $n=14$ & & & \\
\hline 20 to 30 & 24 & 28 & 5 & 57 & 2.0633 & 0.356 \\
\hline$>31$ & 24 & 21 & 9 & 54 & & \\
\hline \multicolumn{7}{|l|}{ MARITAL STATUS } \\
\hline Married & 23 & 20 & 8 & 51 & 1.301 & 0.522 \\
\hline Unmarried & 25 & 29 & 6 & 60 & & \\
\hline \multicolumn{7}{|l|}{ EDUCATION } \\
\hline $\begin{array}{l}\text { No formal education } \\
\text { (NFE) }\end{array}$ & 3 & 3 & 0 & 6 & 3.255 & 0.766 \\
\hline Primary & 17 & 16 & 3 & 36 & & \\
\hline Secondary & 18 & 21 & 6 & 45 & & \\
\hline Tertiary & 10 & 9 & 5 & 24 & & \\
\hline \multicolumn{7}{|l|}{ OCCUPATION } \\
\hline Business & 10 & 9 & 7 & 26 & 9.467 & 0.304 \\
\hline Farmer & 10 & 12 & 0 & 22 & & \\
\hline Skilled & 12 & 11 & 4 & 27 & & \\
\hline Student & 4 & 6 & 1 & 11 & & \\
\hline Unemployed/ Unskilled & 12 & 11 & 2 & 25 & & \\
\hline \multicolumn{7}{|l|}{$\begin{array}{l}\text { NUMBER OF } \\
\text { CHILDREN } \\
\end{array}$} \\
\hline None & 21 & 23 & 6 & 50 & 4.577 & 0.801 \\
\hline One & 14 & 15 & 5 & 34 & & \\
\hline Two & 9 & 9 & 1 & 19 & & \\
\hline Three & 3 & 2 & 1 & 6 & & \\
\hline Four & 1 & 0 & 1 & 2 & & \\
\hline Total & 48 & 49 & 14 & 111 & & \\
\hline
\end{tabular}


At the initiation of Option $\mathrm{B}+$, all pregnant women were recruited and put on prophylactic antiretroviral drugs regardless of the gestational age. In this study, the women were clustered according to their gestational trimester.

\section{Contamination rate}

Table 2: Contamination rate according to the gestational period (in a trimester)

\begin{tabular}{|l|l|c|c|c|c|}
\hline \multirow{2}{*}{$\begin{array}{l}\text { Trimester of Option } \\
\text { B+ introduction }\end{array}$} & \multicolumn{1}{|c|}{ Period of initiation } & \multicolumn{2}{|c|}{ PCR results } & \\
\cline { 3 - 5 } & Positive (\%) & Negative & Total & \multirow{p}{*}{$\boldsymbol{p}$ value } \\
\hline $\mathbf{1}^{\text {st }}$ & December 2015 to February 2016 & $1(4.0)$ & 24 & 25 & 0.583 \\
\hline $\mathbf{2}^{\text {nd }}$ & March 2016 to May 2016 & $1(1.5)$ & 65 & 66 & \\
\hline $3^{\text {rd }}$ & June 2016 to August 2016 & $0(0.0)$ & 20 & 20 & \\
\hline & Total & $2(1.8)$ & 109 & 111 & \\
\hline
\end{tabular}

Of the 111 participants, 25, 66, and 20 were initiated into option $\mathrm{B}+$ within the first, second, and third trimester, respectively. These yielded an HIV positive incidence of $4.00 \%$ and $1.51 \%$ within the first and the second trimester, and $1.80 \%$ in the entire study, amongst babies. Variation of contamination according to the trimester of option $\mathrm{B}+$ was not significant.

\section{Discussion}

This study revealed two cases of infected babies, one in the $1^{\text {st }}$ and another in the $2^{\text {nd }}$ trimester. The explanation could probably be because these babies were already infected before the initiation of Option $\mathrm{B}+[4]$.

Some of the women might be infected during pregnancy. The chance of vertical transmission of HIV is greatly multiplied if a woman gets infected in pregnancy. Disease progression is aggressive if infants acquire the infection before or during the time of delivery [20]. There is an exponential multiplication of the virus with an increased rate of passage of the virus through the placenta [21, 22].

It is also likely that the babies got infected through breast milk for all the babies in this study were breastfed. The percentage of contamination through breast milk is estimated at $15 \%$ [23-25].

In this study, all infection occurred during the $1^{\text {st }}$ and $2^{\text {nd }}$ trimester. Could it also be that the longer the period on ARTs, the lesser compliance, and adherence [25]?

Based on a simulation approach study conducted in Dchang- Cameroon [26], on a projected population of 999,533 pregnant women, the authors projected an infection rate of neonates born to HIV+ mothers on option $\mathrm{B}+$ to be $0.9 \%$ with a coverage of $100 \%, 2 \%$ with a coverage rate of $90 \%$ and $4.0 \%$ with a coverage rate of $80 \%$. These results are similar to those of this study, for there was no statistical difference between the two studies $(p<0.05)$ [26].

Carole Leach-Lemens, in another study, found a comparative rate to this, of $4.1 \%$ compared to $13.3 \%$ among those starting treatment postpartum, in vertical transmission among women starting ART in the first or second trimester [27].

Gupta, in a comparative study, noted that among those women who either never started ART or stopped at any time during or immediately after pregnancy, mother-to-child transmission in 4- to 12-week-old infants was almost tenfold higher than among women on ART during pregnancy, $20.3 \%$, and $2.9 \%$, respectively [27].

In another comparative study, Michael Carter had approximately $11 \%$ of infants whose mothers seroconverted during pregnancy were infected with HIV; the rate of early mother-to-child transmission for mothers with prevalent HIV infection was $2 \%$. These results were similar to those of this study. They stressed on the cost-effectiveness of option B+ [28]. However, the aim of this study was not the costeffectiveness of option $\mathrm{B}+$. We also had similar results to those of Theo Smart's study in Mozambique and 
Malawi, which found that giving ART during pregnancy and breastfeeding reduces the risk of a woman transmitting HIV to her infant to just $2 \%$ [29].

\section{Conclusion}

Mother to child transmission of HIV infection remains worrisome in Cameroon, mostly as the antiretroviral drugs remain unequally distributed over the national territory. Interventions like the use of Antiretroviral (ART) drugs by infected pregnant women, safe delivery practices, and safe infant feeding have helped reduce the risk of transmission to infants (from $40 \%$ to $5 \%$ ) [28, 29].

Without intervention, the risk of MTCT among infants born to women who are HIV positive ranges from $15 \%$ to $45 \%$. Without effective treatment, one-third of infected infants will die before their first birthday, and half will die before two years of age [30].

For the virtual eradication of PMTCT, Strategies should be sought not only to cover the whole of the country, with no dark points left out but also to make tremendous efforts to make sure that all pregnant / breastfeeding mothers effectively receive ARVs and infected children put on therapy.

Although the implementation of option $\mathrm{B}+$ looks more onerous, the long term benefits as far as costeffectiveness is concerned look laudable. Hence, the recommendation of this strategy in in resourcerestricted countries.

\section{Acknowledgments}

We thank all the staff of Atlantic Medical Foundation Hospital Mutengene, mostly Mr. Jaff Napoleon, Mme Tem Phidelia, and Mme Alemkeng. We are indebted to Mme Chi Felicita of the Baptist health services who collects data from the various health institutions of THD. Great gratitude also goes to all the pregnant women who consented to this study.

\section{Author Contributions}

TA, ME, NNT initiated the collaborative project and designed data collection tools. TA, ME, TT, NNCJ, and CFN monitored data collection for the surveys. NFP, CFN keyed and cleaned up the data. NFP and CFN wrote the statistical analysis plan, and CFN analyzed the data. TA, ME, TT drafted the paper. NFP and CFN revised the paper. All authors read and approved the final manuscript.

\section{Funding}

No funding has been obtained from any source to carry out this study.

\section{References}

[1.] Kurth E Ann, Connie Celum, Baeten M Jared, Vermund H Sten, Judith WN: Combination HIV Prevention: Significance, Challenges, and Opportunities. National Institute of Health March 2011, 8(1):62-72.

[2.] Coutsoudis A, Kwaan L, Thomson M.: Prevention of vertical transmission of HIV-1 in resource-limited settings." Expert review of anti-infective therapy". October 2010, 8(1):11631175.

[3.] [http://www.cdc.gov/hiv/resources/reports/hiv_prev_us.htm]

[4.] Joint United Nations Programme on HIV/AIDS (UNAIDS): Global plan towards the elimination of new HIV infections among children by 2015 and keeping their mothers alive. GenevaSwitzerland: UNAIDS; 2011.

[5.] EGPAF, Elizabeth Glaser Pediatric AIDS Foundation: The Cameroon Programme. Working with Women, Children, and Families to End Pediatric AIDS. In. Yaoundé: EGPAF; 2017.

[6.] Cameroon Demographic and Health Survey and Multiple Indicators Cluster Surveys: Cameroon Demographic and Health Survey and Multiple Indicators Cluster Surveys (DHS-MICS). In.; 2011.

[7.] National AIDS Control Committee Central Technical Group, USAID, UNAIDS: The impact of HIV and AIDS in Cameroon through 2020. In. Edited by Nfetam J-BE: National AIDS Control Committee Central Technical Group; 2010. 
[8.] MOH: National Guidelines on the Prevention and Management of HIV in Cameroon. In. Edited by The National AIDS Control Committee and National Tuberculosis Control Programme. Yaoundé: Ministry of Public Health; 2015.

[9.] Global Statistics [https://www/aids.gov/hiv-aids-basics/hiv-aids-101/global-statistics/]

[10.] Fonjong. L: Fostering women's participation in development through Non-governmental efforts in Cameroon. Geographical Journal of the Royal Geographical Society 2001, 167(3).

[11.] UCCC: United Councils and Cities of Cameroon. In. Yaoundé: Ministry of Territorial Administration and Decentralisation; 2014.

[12.] Ayuk Betrand Tambe, Leonie Dapi Nzefa, Nchang Allo Nicoline.: Childhood Diarrhoea Determinants in Sub-Saharan Africa: A Cross Sectional Study of Tiko-Cameroon. Challenges 2015, 6:229-243.

[13.] Eposi Christiana Haddison, Georges Nguefack-Tsagué, Michel Noubom1, Wilfried Mbatcham, Peter Martins Ndumbe, FrançoisXavier Mbopi-Kéou.: Voluntary counseling and testing for HIV among high school students in the Tiko health district, Cameroon. Pan Afr Med J 2012.

[14.] Stephen Ekure Takow JA, Rebecca Enow-Tanjong, Mesembe MT, Ikomey GM, Ndip LM, Mbuagbaw JC, Ndumbe PM: Time for Option B+? Prevalence and characteristics of HIV infection among attendees of 2 antenatal clinics in Buea, Cameroon. Journal of the International Association of Providers of AIDS Care 2015.

[15.] Nigel C Rollins, Renaud Becquet, Joanna Orne-Gliemann, Sam Phiri, Chika Hayashi, April Baller, and Nathan Shaffer, on behalf of the INSPIRE Team.: Defining and Analyzing Retention-inCare Among Pregnant and Breastfeeding HIV-Infected Women: Unpacking the Data to Interpret and Improve PMTCT Outcomes. Journal of Acquired Immune deficiency Syndrome 2014, 67(Supplement 2):S150-S156.

[16.] Gottfried Hirnschall, Meg Doherty, Nathan Shafferi.: Is Option B+ the best choice? The Lancet n.d, 381(9874).

[17.] Lisa O'Brien, Nathan Shaffer, Nalinee Sangrujee \& Taiwo O Abimbola.: Surcoût du passage de l'Option $B$ à l'Option B+ pour la prévention de la transmission du VIH de la mère à l'enfant. AIDS 2016, 30(6):953-962.

[18.] John GC, Kreiss J.: Mother-to-child transmission of human immunodeficiency virus type 1. Epidemiol Rev 1996, 18:149-157.

[19.] Becquet R, Bland R, Leroy V, Rollins NC, Ekouevi DK, Coutsoudis A.: Duration, pattern of breastfeeding and postnatal transmission of HIV: pooled analysis of individual data from West and South African cohorts. PLoS One 2009, 4( e7397).

[20.] Drake L Alison, Anjuli Wagner, Barbra Richardson, John-Stewart. G: Incident HIV during Pregnancy and Postpartum and Risk of Mother-to-Child HIV Transmission: A Systematic Review and Meta-Analysis. PLoS Med 2014, 11(2).

[21.] Soilleux EJ, Coleman N.: Transplacental transmission of HIV: a potential role for HIV binding lectins. Int J Biochem Cell Biol 2003, 35(3):283-287.

[22.] Moodley D, Esterhuizen T, Reddy L, Moodley P, Singh B.: Incident HIV infection in pregnant and lactating women and its effect on mother-to-child transmission in South Africa. $J$ Infect Dis 2011, 203:1231-1234.

[23.] Coutsoudis A, Pillay K, Spooner E, Kuhn L, Coovadia HM: Influence of infant-feeding patterns on early mother-to-child transmission of HIV-1 in Durban, South Africa: a prospective cohort study. South African Vitamin A Study Group. Lancet 1999, 354:471-476.

[24.] Neh-Fru Celestina Tassang: Les réseaux de solidarité face a la crise économique et la mondialisation: parenté, associations culturelles et ethnicité au Cameroun. University of Yaoundé 1; 2010.

[25.] Hermine L Ngueana Nguefack, Henri Gwet, Sophie Desmonde, Odile Ouwe Missi Oukem-Boyer, Céline Nkenfou, Mathurin Téjiokem, Patrice Tchendjou, Irénée Domkam, Valériane Leroy, Ahmadou Alioum.: Estimating mother-to-child HIV transmission rates in Cameroon in 2011: a computer simulation approach, Inserm U897 Modeling Infectious Diseases in Low-Income Countries Study Group. 2011. 
[26.] Carole Leach-Lemens: Conference on Retroviruses and Opportunistic Infections. In: 2016; Boston, USA.

[27.] Carter Michael: Many South African women become infected with HIV during pregnancy posing high risk of transmission to their infants. AIDSMAP 2015.

[28.] Theo Smart: BAN Study: Giving ART to Mothers or ARV Prophylaxis to Infants during Breastfeeding Equally Effective At Reducing HIV Transmission. AIDSMAP 2009.

[29.] Knowledge for Health: Prevention of Mother-to-Child Transmission. 2012.

[30.] WHO UNAIDS: A progress report on the Global Plan towards the elimination of new HIV infections among children by 2015 and keeping their mothers alive. In.; 2012. 